\title{
HUBUNGAN STUNTING DENGAN PRESTASI BELAJAR ANAK SEKOLAH DASAR NEGERI KIRU-KIRU KECAMATAN SOPPENG RIAJA KABUPATEN BARRU
}

\section{Stunting Relationship with the Learning Achievements of Kiru-Kiru Elementary School Children in Soppeng Riaja District Barru}

\author{
Nadirawati, Haniarti, Usman \\ Program Studi Kesehatan Masyarakat Fakultas Ilmu Kesehatan Universitas Muhammadiyah \\ Parepare \\ (irha_nadira@yahoo.com)
}

\begin{abstract}
ABSTRAK
Stunting merupakan hasil dari kekurangan asupan nutrisi dan penyakit infeksi secara terus menerus, yang mana jika stunting dibiarkan akan mempengaruhi perkembangan kognitif, penurunan IQ, apatis, tidak percaya diri,sulit berkonsentrasi dan rendahnya prestasi akademik. Hasil pemantauan status gizi (PSG) 2015 prevalensi stunting di Provinsi Sulawesi Selatan Kabupaten Barru terdapat 99 kasus (33\%). Tujuan penelitian ini adalah untuk mengetahui hubungan stunting dengan prestasi belajar anak Sekolah Dasar Negeri Kiru-Kiru Kec.Soppeng Riaja Kab.Barru.Penelitian ini merupakan penelitian observasional analitik dengan rancangan cross sectional study. Sampel dalam penelitian ini adalah semua siswa SDN Kiru-Kiru sebanyak 73 responden yang memenuhi kriteria inklusif dengan teknik total sampling, pengumpulan data melalui wawancara yang mengacu pada kuesioner dan observasi secara langsung. Analisis data dengan uji chi squareyang disajikan dalam bentuk tabel dan narasi.Hasil penelitian diperoleh ada hubungan stunting dengan prestasi belajar anak Sekolah Dasar Negeri Kiru-Kiru Kecamatan Soppeng Riaja Kabupaten Barru dengan $(\mathrm{p}=0,013)$. Berdasarkan hasil penelitian yang diperoleh, peneliti mengharapkan adanya kerjasama yang baik antara orang tua dan anak untuk menjaga asupan gizi agar terhindar dari Stunting.
\end{abstract}

\section{Kata kunci : Stunting, prestasi belajar}

\section{ABSTRACT}

Stunting is a result of a continuous lack of nutritional intake and infectious diseases, which if stunting is allowed will affect cognitive development, decreased IQ, apathy, lack of confidence, difficulty concentrating and low academic achievement. The results of monitoring the 2015 nutritional status (PSG) of stunting prevalence in South Sulawesi Province in Barru Regency were 99 cases (33\%). The purpose of this study was to determine the stunting relationship with the learning achievements of Kiru-Kiru State Elementary School children in Soppeng Riaja District, Barru Regency.This study was an analytic observational study with a cross sectional study design. The sample in this study were all students of SDN Kiru-Kiru as many as 73 respondents who met the inclusive criteria with the technique of total sampling, collecting data through interviews that refer to the questionnaire and direct observation. Data analysis with chi square test is presented in the form of tables and narratives.The results showed that there was a stunting relationship with the learning achievement of Kiru-Kiru State Elementary School children in Soppeng Riaja District, Barru Regency $(p=0.013)$. Based on the results of the research obtained, the researchers expected a good collaboration between parents and children to maintain nutritional intake to avoid Stunting.

Keywords : Stunting, Learning achievement 



\section{PENDAHULUAN}

Masalah anak pendek (stunting) merupakan salah satu permasalahan gizi yang dihadapi di dunia, khususnya di negara-negara miskin dan berkembangan, Stunting menjadi permasalahan karena berhubungan dengan meningkatnya risiko terjadinya kesakitan dan kematian, perkembangan otak suboptimal sehingga perkembangan motorik terlambat dan terhambatnya pertumbuhan. ${ }^{1}$ Menurut hasil Pemantauan Status Gizi (PSG) 2015 yang dilakukan oleh Kementerian Kesehatan, sebesar 29\% balita Indonesia termasuk kategori pendek. Untuk anak usia sekolah, terjadi fluktuasi prevalensi pendek, 32\% tahun 2001, menjadi 30\% tahun 2004, meningkat menjadi $33,4 \%$ pada tahun 2007, menurun kembali pada tahun 2010 menjadi $28,3 \%$, namun kembali meningkat pada tahun 2013 menjadi 31,7\%. Berdasarkan Riskesdas 2013, didapatkan prevalensi status gizi pendek anak usia sekolah (6-12 tahun) di Indonesia sebesar 30,7 persen. Berdasarkan data yang diterima dari Dinas Kesehatan Provinsi Sulawesi Selatan, jumlah stunting di Indonesia pada tahun 2015 sebanyak 29,0\%, tahun 2016 sebanyak 27,5\% dan tahun 2017 sebanyak 29,6\%. Anak-anak yang stunting (pendek) karena kurang gizi ternyata lebih banyak yang terlambat masuk sekolah, lebih sering absen, dan tidak naik kelas. ${ }^{2}$ Lebih dari sepertiga $(36,1 \%)$ anak di Indonesia tergolong pendek ketika memasuki usia sekolah. Stunting (rendahnya tinggi badan menurut umur) mencerminkan pertumbuhan linier yang buruk. Kondisi ini terakumulasi sejak periode pre- dan postnatal yang disebabkan oleh buruknya gizi dan kesehatan. Stunting pada usia dini akan mengakibatkan efek merugikan pada kecerdasan, perkembangan psikomotorik, keterampilan motorik halus dan integrasi neurosensorik.pengaturan makanan pada anak yang bergizi baik, seimbang dan beraneka ragam jenis akan memastikan kecukupan gizinya. Jika anak sering sakit, atau kurang gizi akan sering absen di kelas, sehingga mengalami gangguan belajar dan keterlambatan dalam menyelesaikan sekolah. Salah satu cara menilai kualitas seorang anak adalah dengan melihat prestasi belajarnya di sekolah. ${ }^{3}$

Data Riset Kesehatan Dasar (RISKESDAS) tahun 2010 di Provinsi Sulawesi Selatan untuk kategori sangat pendek $15,8 \%$ dan pendek $23,1 \%$, sehingga prevalensi stunting 38,9\%. ${ }^{4}$ Berdasarkan hasil Riskesdas 2013 Provinsi Sulawesi Selatan prevalensi stunting umur 5-12 tahun untuk kategori sangat pendek $10,8 \%$ dan pendek $23,2 \%$, sehingga prevalensi stunting di Provinsi Sulawesi Selatan sebesar 34\%, dari hasil penelitian di Wilayah Sekolah Negeri Kiru-Kiru Kecamatan Soppeng Riaja Kabupaten Barru tahun 2018 tercatat sebanyak $31(42,5 \%)$ anak yang berstatus gizi pendek (stunting).

Stunting merupakan gangguan pertumbuhan dan perkembangan dalam jangka waktu yang sangat lama (kronis) akibat tidak terpenuhinya nutrisi dalam tubuh hal ini menyebabkan penurunan 
intelegensia (IQ) sehingga prestasi belajar menjadi rendah dan tidak dapat melanjutkan sekolah. Sehingga dampaknya setelah dewasa peluang gagal tes wawancara pekerjaan menjadi lebih besar sehingga angka pengangguran semakin meningkat dan akan menjadi beban negara. Oleh karena itu, peneliti tertarik untuk meneliti hubungan stunting dengan prestasi belajar anak Sekolah Dasar Negeri Kiru-Kiru di Kecamatan Soppeng Riaja Kabupaten Barru.

\section{METODE PENELITIAN}

Jenis penelitian yang digunakan adalah penelitian observasional analitik dengan rancangan cross sectional, untuk menganalisis hubungan antara stunting dengan prestasi belajar pada anak Sekolah Dasar Negeri Kiru-Kiru mulai dari kelas I VI di Kecamatan Soppeng Riaja Kabupaten Barru. Adapun waktu pelaksanaannya pada tanggal 1 sampai 7 juni 2018. Populasi pada penelitian ini adalah semua peserta didik Sekolah Dasar Negeri Kiru-Kiru Kecamatan Soppeng Riaja Kabupaten Barru yang berjumlah 89 siswa. Data yang di peroleh dari sekolah dasar negeri kiru-kiru tentang hubungan stunting dengan prestasi belajar anak sekolah dasar negeri Kiru-Kiru Kecamatan Soppeng Riaja Kabupaten Barru, identitas siswa dan tinggi badan. nilai ratarata raport semester ganjil yang berkaitan dengan penelitian saya.

\section{HASIL PENELITIAN}

Penelitian ini dilakukan di Sekolah Dasar Negeri Kiru-kiru Kecamatan Soppeng
Riaja Kabuapten Barru. Pengumpulan data dilaksanakan mulai 1 Juni sampai 7 Juni 2018. Pengmpulan data pada penelitian ini dilakukan dengan mengukur tinggi badan responden menggunakan kuesioner sesuai dengan desain penelitian yang digunakan yaitu metode observasional analitik dengan rancangan cross sectional dengan menggunakan teknik total sampling. Responden dalam penelitian ini adalah semua peserta didik Sekolah Dasar Negeri Kiru-Kiru yang memenuhi kriteria inklusif berjumlah 73 dari 89 siswa..

Distribusi responden Berdasarkan Umur, jenis kelamin dan kelas (Tabel 1), Tabel 1 diperoleh distribusi responden berdasarkan umur yaitu yang tertinggi yaitu 8 tahun sebanyak 17 responden atau $(23,3 \%)$ sedangkan yang terendah yaitu umur 7 tahun 1 responden atau $(1,4 \%)$. Untuk distribusi responden jenis kelamin yaitu laki-laki sebanyak 31 responden atau $(42,5 \%)$ dan perempuan sebanyak 42 responden atau (57,5\%). Dan untuk disribusi responden berdasarkan kelasdiperoleh yang tertinggi kelas 3 sebanyak 17 responden atau $(23,3 \%)$ sedangkan yang terendah kelas 5 sebanyak 9 responden atau $(12,3 \%)$.

Tabel 2 menunjukkan responden yang status gizi pendek (stunting) yaitu yang berstatus normal sebanyak 42 responden atau $(57,5 \%)$ sedangkan kategori stunting sebanyak 31 responden atau $(42,4 \%)$. Berdasarkan data pada Tabel 3 tingkat prestasi belajar anak di sekolah didapatkan hasil yang berprestasi baik sebanyak 31 
responden atau $(42,5 \%)$ dan yang berprestasi kurang 42 responden atau $(57,5 \%)$.

Data pada Tabel 4 menunjukkan bahwa dari 73 responden dari hasil penelitian yang dilakukan di SDN Kiru-Kiru Kecamatan Soppeng Riaja Kabupaten Barru yang berstatus gizi normal dimana yang berprestasi baik sebanyak 23 responden atau $(54,8 \%)$ yang berstatus gizi normal dimana yang berprestasi kurang 19 responden atau $(45,2 \%)$, dan yang termasuk kategori stunting dimana yang berprestasi baik sebanyak 8 responden atau $(25,8 \%)$, yang termasuk kategori stunting dimana yang berprestasi kurang 23 responden atau $(74,2 \%)$.

\section{PEMBAHASAN}

Berdasarkan hasil penelitian yang dilakukan peneliti menunjukkan karakteristik berdasarkan umur kategori yang paling dominan adalah umur 8 tahun. Usia sekolah merupakan usia emas kedua bagi pertumbuhan anak baik fisik maupun mental yang berpengaruh pada masa depan, kekurangan nutrisi seperti stunting akan menyebabkan rendahnya prestasi belajar. Jenis kelamin menentukan pula besar kecilnya kebutuhan status gizi seseorang. Pria lebih banyak membutuhkan zat tenaga danprotein dibandingkan wanita. Pria lebih sanggup mengerjakan pekerjaan berat yang tidak biasa dilakukan wanita. Selama masa bayi dan anak-anak, anak perempuan cenderung lebih rendah kemungkinannya menjadi stunting dan severe stunting dari pada anak laki-laki, selain itu bayi perempuan dapat bertahan hidup dalam jumlah ang lebih besar dari pada bayi lakilaki dikebanyakan Negara berkembang termasuk Indonesia. ${ }^{5}$

Pendidikan orang tua merupakan faktor yang paling penting. Hal ini menunjukkan, pendidikan orang tua akan berpengaruh terhadap pengasuhan anak, karena dengan pendidikan yang tinggi pada orang tua akan memahami pentingnya peranan orang tua dalam pertumbuhan anak. Tinggi rendahnya pengetahuan ibu sangat berpengaruh terhadap perawatan kesehatan saat hamil dan setelah melahirkan serta sangat berpengaruh terhadap kesehatan dan gizi anak-anaknya dan keluarganya. Pendidikan juga berpengaruh terhadap pekerjaan. Pekerjaan dapat mempengaruhi konsumsi pangan pada anak, jika pekerjaan orang tua seperti PNS dan TNI/POLRI dapat menghasilkan pendapatan yang tetap setiap bulannya, sehingga orang tua dapat mengatur pembelanjaan konsumsi pangan dengan baik. Sedangkan pekerjaan seperti wiraswasta, pedagang dan petani penghasilannya.

Partisipasi orang tua berpengaruh terhadap proses belajar anak dan prestasi anak yang akan dicapai, orang tua yang tidak memperhatikan pendidikan dan kebutuhan dalam belajar, tidak mengatur waktu belajar, tidak menyediakan atau melengkapi alat belajarnya dapat menyebabkan anak kurang atau bahkan tidak berhasil dalam belajarnya. Pengaturan makanan yang bergizi pada anak, seimbang dan beraneka jenis akan 
memastikan kucukupan gizinya, sehingga anak tidak sering sakit atau kurang gizi maka akan terhindar dari gangguan belajar dan tidak sring absen di kelas.

Hubungan status gizi pendek (stunting) dengan prestasi belajar menunjukkan 73 responden dari hasil penelitian yang dilakukan di SDN Kiru-Kiru Kecamatan Soppeng Riaja Kabupaten Barru yang berada pada kategori status gizi normal dimana prestasi baik sebanyak 23 responden atau $(54,8 \%)$, pada kategori normal dimana prestasi belajar kurang yaitu 19 responden atau $(45,2 \%)$ dan yang termasuk kategori stunting dimana yang berprestasi baik sebanyak 8 responden atau $(25,8 \%)$, yang termasuk kategori stunting dimana yang berprestasi kurang 23 responden atau $(74,2 \%)$. Berdasarkan hasil uji statistik dengan menggunakan uji chi square maka diperoleh $\mathrm{p}=0,013$ dengan taraf signifikan 95\%, karena $\mathrm{p}=0,013<0,05$ maka $\mathrm{Ha}$ diterima dan Ho ditolak. Ini berarti ada hubungan antara stunting dengan prestasi belajar anak sekolah SDN Kiru-Kiru.

Hasil yang diperoleh dari penelitian ini menunjukkan bahwa dari 31 siswa yang stunting terdapat 23 siswa yang berprestasi kurang. Hal ini menunjukkan bahwa stunting merupakan salah satu faktor yang mempengaruhi prestasi belajar anak. Prestasi belajar siswa juga oleh dipengaruhi peran orang tua dalam mendidik anak. dari hasil penelitian yang diperoleh masih ada orang tua siswa yang tidak membimbing anak pada waktu belajar yang disebabkan berbagai macam faktor di antaranya, orang tua yang berpendidikan rendah tidak dapat membantu anak dalam membimbing semua pelajaran, orang tua siswa yang sibuk karena pekerjaan sehingga melupakan tanggung jawab membimbing anak, tidak memperhatikan kebutuhan anak, selain itu faktor kebiasaan belajar di luar maupun di dalam rumah juga mempengaruhi siswa yang stunting.

Hal ini di dukung oleh Sarci (2013) Prestasi belajar seorang anak juga dipengaruhi berbagai macam faktor yaitu faktor yaitu faktor lingkungan, gen, faktor kebiasaan belajar diluar maupun didalam rumah, faktor lain yang juga mempengaruhi adalah sosial ekonomi, proses dan cara belajar serta rendahnya kualitas penyerapan dan penguasaan materi yang diberikan oleh guru di Sekolah oleh siswa yang stunting. ${ }^{6}$

$$
\text { Stunting adalah gangguan }
$$
pertumbuhan dan perkembangan dalam jangka waktu yang sangat lama (kronis) akibat pemberian makanan yang tidak sesuai dengan kebutuhan energi, anak yang dikatakan stunting jika nilai Z-score $<-2$ $\mathrm{SD}$, sehingga anak yang menderita stunting berpengaruh pada prestasi belajarnya. Hal ini sejalan dengan penelitian yang dilakukan Prisca Petty Arfines, dan Fithia Dyah Puspitasari (2017) mengenai Hubungan Stunting dengan Prestasi Belajar Anak Sekolah Dasar di Daerah Kumuh, Kotamadya Jakarta Pusat. menunjukkan bahwa z-score untuk TB/U (parameter stunting) dan tingkat konsentrasi anak yang memiliki hubungan secara signifikan dengan rata-rata pengetahuan (parameter prestasi belajar) dengan kekuatan hubungan linier 
yang lemah ( $\mathrm{r}=0.177)$ untuk parameter stunting dan hubungan yang lebih kuat untuk konsentrasi belajar dengan pengetahuan $(\mathrm{r}=0.510){ }^{7}$

Stunting merupakan wujud dari adanya gangguan pertumbuhan pada tubuh, bila ini terjadi maka salah satu organ tubuh yang cepat mengalami risiko adalah otak. Dalam otak terdapat sel-sel saraf yang sangat berkaitan dengan respons anak termasuk dengan melihat, mendengar, dan berfikir selama proses belajar. Usia sekolah dasar merupakan usia emas kedua bagi pertumbuhan anak baik fisik maupun mental yang berpengaruh bagi masa depan sebagai generasi penerus bangsa. Keadaan gizi kurang seperti stunting yang dialami oleh anak usia sekolah akan mempengaruhi kamampuan daya tangkap anak dalam mengikuti pelajaran di sekolah dan akan mempengaruhi prestasi belajarnya Sarci (2013). Anak usia sekolah merupakan usia emas kedua bagi pertumbuhan anak baik fisik maupun mental yang berpengaruh pada masa depan. Keadaan dimana kekurangan asupan nutrisi seperti stunting, jika dibiarkan akan mempengaruhi kemampuan daya

\section{DAFTAR PUSTAKA}

1. Unicef. Improving Child Nutrition The Achievable Imperative for Global Progress. 2013. [Diakses tanggal 19 April 2018]. Available at: pada www.unicef.org/media/files/nutrition report 2013.Pdf. tangkap anak dalam mengikuti pelajaran di sekolah dan tidak percaya diri sehingga menyebabkan rendahnya prestasi akademik. Hal ini didukung oleh pendapat Almatsier (2001) yang mengatakan bahwa kekurangan gizi dapat mengakibatkan gangguan fungsi otak secara permanen. ${ }^{8}$

\section{KESIMPULAN DAN SARAN}

Berdasarkan hasil penelitian yang telah dilakukan, maka dapat disimpulkan bahwa ada hubungan stunting dengan prestasi belajar di Sekolah Dasar Negeri Kiru-Kiru Kecamatan Soppeng Riaja kabupaten Barru, dengan $\mathrm{p}=0,013<0,05$. Berdasarkan hasil penelitian, analisis data dan kesimpulan di atas maka di sarankan, diharapkan bagi orang tua untuk lebih memperhatikan status gizi anak dan membantu atau membimbing anak untuk dapat meningkatkan potensi anak, kecerdasan dan rasa percaya diri anak.diharapkan kepada pihak sekolah untuk mengajarkan kepada siswa tentang makanan yang bergizi untuk dapat mencapai prestasi yang baik.

2. Khomsan A. Ekologi Masalah Gizi, Pangan, dan Kemiskinan. Bandung: Alfabeta; 2012.

3. Junaedi P. 2004. Kota yang Sehat untuk Anak. J Kesehatan Perkota; 11(1).

4. Kementerian Kesehatan Republik Indonesia. Riset Kesehatan Dasar (RISKESDAS); 2010. [Diakses pada 
tanggal 8 April 2018]. Available at: pada http:// www. riskesdas. litbang. depkes. go. id / download / Tabel Riskesdas 2010. pdf

5. Ramli, Kingsley EA, Inder KI, Bowe SJ, Jacobs J, Dibley MJ. Prevalensi and Risk Factors for Stunting and Severe Stunting Among Under Five in North Maluku Province of Indonesia; . 2009. [Diakses pada tanggal 8 April 2018]. Available at : http : // www. ncbi. nlm. nih.gov.

6. Sarci M, Intje P. Analisis Determinan dan Pengaruh Stunting terhadap Prestasi
Belajar Anak Sekolah di Kupang. Jurnal Gizi dan Pangan. 2013; 8 (1).

7. Prisca Petty A, Fithia Dyah P. 2017. Puslitbang Upaya Kesehatan Masyarakat; 2017. [Diakses pada tanggal 8 April 2018]. Available at: http://dx.doi.org/10.22435/bpk.v45il.579 8.45-52.

8. Almatsier S. Prinsip Dasar Ilmu Gizi. Cetakan ke-5. Jakarta: Gramedia Pustaka Utama; 2001. 


\section{LAMPIRAN}

Tabel 1. Distribusi karakteristik responden berdasarkan umur, jenis kelamin dan kelas di SDN Kiru-Kiru

\begin{tabular}{lll}
\hline Karakteristik & $\mathrm{n}$ & $\%$ \\
\hline Umur (tahun) & & 1,4 \\
\hline 7 & 1 & 23,3 \\
8 & 17 & 17,8 \\
9 & 13 & 20,5 \\
10 & 15 & 12,3 \\
11 & 9 & 19,2 \\
12 & 14 & 5,5 \\
13 & 4 & \\
\hline Jenis kelamin & & 42,5 \\
laki-laki & 31 & 57,5 \\
Perempuan & 42 & \\
\hline Kelas & & 13,7 \\
1 & 10 & 13,7 \\
2 & 10 & 23,3 \\
3 & 17 & 16,4 \\
4 & 12 & 12,3 \\
5 & 9 & 20,5 \\
6 & 15 & 100 \\
\hline Total & 73 &
\end{tabular}

Sumber : Data Primer Tahun 2018

Tabel 2. Distribusi responden berdasarkan pekerjaan orang tua di SDN Kiru-Kiru

\begin{tabular}{ll|l|l|l}
\hline Pekerjaan orang tua & \multicolumn{2}{l}{ Ayah } & \multicolumn{3}{c}{ Ibu } \\
\hline tidak bekerja (IRT) & $\mathrm{n}$ & $\%$ & $\mathrm{n}$ & $\%$ \\
PNS/TNI/polri/pensiun & 2 & 2,7 & 47 & 64,4 \\
karyawan swasta & 5 & 6,8 & 2 & 2,7 \\
Pedagang & 13 & 17,8 & 0 & 0 \\
Petani & 4 & 5,5 & 6 & 8,2 \\
lain-lain & 34 & 46,6 & 0 & 0 \\
\hline Total & 15 & 20,5 & 18 & 24,7 \\
\hline \multicolumn{1}{c}{$S$} & 73 & 100 & 73 & 100 \\
\hline
\end{tabular}

Sumber : Data Primer Tahun 2018 
Tabel 3.Distribusi responden berdasarkan pendidikan orang tua di SDNKiru-Kiru

\begin{tabular}{lllll|}
\hline Pendidikan orang tua & Ayah & \multicolumn{3}{c}{ Ibu } \\
\hline Tidak sekolah & $\mathrm{n}$ & $\%$ & $\mathrm{n}$ & $\%$ \\
Tidak tamat SD & 1 & 1,4 & 0 & 0 \\
SD & 5 & 6,8 & 8 & 11 \\
SMP & 11 & 15,1 & 12 & 16,4 \\
SMA & 9 & 12,3 & 45 & 61,6 \\
Perguruan tinggi & 35 & 47,9 & 8 & 11 \\
\hline Total & 12 & 16,4 & 8 & 11 \\
\hline \multicolumn{1}{c}{ Sumber: } & 73 & 100 & 73 & 100 \\
\hline
\end{tabular}

Sumber : Data Primer Tahun 2018

Tabel 4. Distribusi responden berdasarkan peran orang tua dalam mendidik anak di SDN

\begin{tabular}{lll} 
& Kiru-Kiru & \\
\hline Peran orang tua dalam mendidik anak & $\mathrm{n}$ & $\%$ \\
\hline Orang tua dalam memberikan bimbingan & & \\
Ya & 43 & 58,9 \\
kadang-kadang & 27 & 37 \\
Tidak pernah & 3 & 4,1 \\
\hline Orang tua membimbing seluruh pelajaran & & \\
Ya & 36 & 49,3 \\
hanya sebagian & 34 & 46,6 \\
tidak satupun & 3 & 4,1 \\
\hline orang tua dalam menanyakan hasil belajar & & \\
ya, menyakan & 39 & 53,4 \\
kadang-kadang & 31 & 42,5 \\
tidak pernah & 3 & 4,1 \\
\hline waktu orang tua membimbing & & \\
setiap hari & 49 & 67,1 \\
dua kali seminggu & 3 & 4,1 \\
tidak menentu & 21 & 28,8 \\
\hline Waktu siswa belajar di rumah & & \\
malam hari & 70 & 95,9 \\
siang hari & 2 & 2,7 \\
tidak pernah belajar di rumah & 1 & 1,4 \\
\hline Pendapat orang tua dalam kemajuan belajar & & \\
merasa senang & 71 & 97,3 \\
biasa saja & 2 & 2,7 \\
\hline Orang tua dalam memenuhi peralatan sekolah & & \\
iya,selalu memenuhi & 55 & 75,3 \\
kadang-kadang & 18 & 24,7 \\
\hline Total & 73 & 100 \\
\hline$\quad$ Sumber: Data Primer & &
\end{tabular}

Sumber : Data Primer Tahun 2018 
Tabel 5. Distribusi responden berdasarkan jumlah hari absen di SDN Kiru-Kiru.

\begin{tabular}{lll}
\hline jumlah hari absen & $\mathrm{n}$ & $\%$ \\
\hline 0 & 31 & 42,5 \\
1 & 12 & 16,4 \\
10 & 1 & 1,4 \\
2 & 10 & 13,7 \\
3 & 8 & 11 \\
4 & 1 & 1,4 \\
5 & 4 & 5,5 \\
7 & 5 & 6,8 \\
8 & 1 & 1,4 \\
\hline Total & 73 & 100 \\
\hline
\end{tabular}

Sumber : Data Primer Tahun 2018

Tabel 6. Distribusi responden status gizi pendek (stunting) di SDN Kiru-Kiru

\begin{tabular}{lll}
\hline Status gizi pendek (stunting) & $\mathrm{n}$ & $\%$ \\
\hline Normal & 42 & 57,5 \\
Stunting & 31 & 42,5 \\
\hline Total & 73 & 100 \\
\hline
\end{tabular}

Sumber : Data Primer Tahun 2018

Tabel 7. Distribusi responden berdasarkan prestasi belajar anak di sekolah di SDN KiruKiru

\begin{tabular}{lll}
\hline Prestasi belajar & $\mathrm{n}$ & $\%$ \\
\hline Baik & 31 & 42,5 \\
Kurang & 42 & 57,5 \\
\hline Total & 73 & 100 \\
\hline
\end{tabular}

Sumber : Data Primer Tahun 2018

Tabel 8. Hubungan stunting dengan prestasi belajar yang dilakukan di SDN Kiru-Kiru Kabupaten Barru

\begin{tabular}{lcccccccc}
\hline & \multicolumn{9}{c}{ prestasi belajar } & & \multirow{2}{*}{ Total } & \multirow{2}{*}{$P$} \\
\cline { 2 - 6 } Status gizi pendek (stunting) & \multicolumn{3}{c}{ Baik } & \multicolumn{3}{c}{ Kurang } & & \\
\cline { 2 - 7 } & $\mathrm{n}$ & $\%$ & $\mathrm{n}$ & $\%$ & $\mathrm{n}$ & $\%$ & \\
\hline Normal & 23 & 54,8 & 19 & 45,2 & 42 & 100 & \multirow{2}{*}{0,013} \\
Stunting & 8 & 25,8 & 23 & 74,2 & 31 & 100 & \\
\hline Total & 31 & 42,5 & 42 & 57,5 & 73 & 100 & \\
\hline
\end{tabular}

Sumber : Data Primer Tahun 2018 